\title{
The Effectiveness of Rural Investment of Self Help Groups (SHG) on the Economic and Social Wellbeing of Women: A Case Study of Katete District - Eastern Province
}

\author{
Hastings Munyenyembe \\ School of Business and Management, PhD, Texila American University-Zambia
}

\begin{abstract}
Poverty and unemployment are the major problems of any under developed countries, to which Zambia is no exception. The rate of growth of women and youth employment in less developed countries is very low. This is because of the low growth rate of new and productive employment. However, the more attractive scheme trying to solve poverty matrix with less effort is "Self Help Group" (SHG). Self Help Group is a tool to remove poverty and improve the women entrepreneurship and financial support. It is a small economically homogeneous affinity group of the rural poor women voluntarily coming together to save a small amount of money regularly, which is deposited in a common fund to meet members emergency needs and to provide collateral free loans decided by the group. Self Help Groups enhances the equality of status of women as participants, decision-makers and beneficiaries in the democratic, economic, social and cultural spheres of life. This study is mainly focusing on the Self Help Group formation, women entrepreneurship and economic empowerment of women after them joining Self Help Groups in Katete district, Eastern Province - Zambia. Katete district women development association (KDWDA) is one of the pioneers for the implementation of the development of women in Katete rural areas. Presently there are 7 Clusters in Katete district consisting of 70 Self Help Groups. Of these, the best five villages were selected for this study, because the SHGs in these villages were functioning in a very successful manner. There are 1, 190 members from 70 Self Help Groups in Katete district. Among them, a total of 80 respondents were selected based on 5 members from each SHG of the selected four clusters by using convenient sampling method.
\end{abstract}

Key words: Self Help Group, Rate of Growth of women, Youth Employment, Rural investment, and Social Wellbeing.

\section{INTRODUCTION}

$\mathrm{T}$ he self-help group (SHG) approach is a new paradigm into the field of rural development in Zambia which main objectives are to increase the well-being of the poor people, provide access to resources and credit, increase selfconfidence, self-esteem and increase their creditability in all aspects of lives. This concept was introduced by Care International working in collaboration with local NGOs such as Katete District Women Development Association (KDWDA), COMACO, and government line ministries in the
Year 2010. While the groups have continued operating under the support of NGOs and government ministries, little research has been done to ascertain the Effectiveness of these SHGs on social economic wellbeing of women folks in Katete district.

Self-help group is a voluntary and self-managed group of women, belonging to similar socio-economic characteristics, who come together to promote savings among themselves. The poverty alleviation intervention of the SHG is in the form of undertaking economic programmes to provide employment, giving micro finance services to the poor so that they can get themselves acquainted with skills and occupational diversification.

This research aims to explore the effectiveness of SHG in poverty reduction, particularly the assessment of its effectiveness on social economic wellbeing of women involved in these SHGs; the performance of group businesses run by SHGs, and individual women in income generation; and the challenges rural women face in attaining the full benefit of the SHG concept in Katete district of Zambia. The hypotheses that had been taken to Fulfill the work was that the self-help groups have no effectiveness on poverty alleviation and the availability of micro credit was not adequate to members of the self-help groups.

\section{Problem Statement}

Critically considering women increased vulnerability and higher levels of poverty. Micro-credit and savings programs have become very popular lately. Many people believe that micro-loans are a very promising way of ending poverty and that enabling the poor to save helps make them less vulnerable. The development of "third world" countries is a worldwide concern and important to Zambia as one of the developing countries. There are many different theories about what works and what does not and what projects aid should be invested in. The development field is vast, controversial, and confusing and additional research is needed to discover how effective different projects are. Again, focusing on women and development is important considering their subordinate 
status and difficulty in contributing to development in Zambia.

Self-Help Groups are an ideal choice of topic to study, therefore, because they focus on poverty, especially rural poverty and the poverty of women, provide the poor with access to savings and loans, and have the potential to contribute to development and the development of women.

\section{Objectives of This Study}

\section{General Objective}

To investigate the effectiveness of Self Help Groups (SHGs) on the economic and social wellbeing of women folk in Katete District of eastern province.

\section{Specific Objectives}

This study specific objectives are:

i. To examine the economic viability of group businesses run by SHGs of Katete districts

ii. To investigate the effectiveness of SHGs on the economic and social wellbeing of women folks in Katete district.

iii. To investigate the level of challenges faced by SHG members in Katete district.

\section{Research Hypothesis}

HO: Self Help Groups had no effectiveness on the socioeconomic wellbeing of women folks in Katete district

HA: Self Help Groups in rural areas had an effectiveness impact on socio-economic wellbeing of women folks in Katete district.

\subsection{Rationale/significance}

Empowerment is not essentially political alone; it is a process having personal, economic, social and political dimensions with personal empowerment being the core of the empowerment process. In fact political empowerment will not succeed in the absence of economic empowerment at household level. The Scheme of Micro-financing through SHGs create empowerment promoting conditions for women to move from positions of marginalisation within household to decision making process.

The out-come of the study therefore would be useful for project facilitators and responsible government department in the line ministry to provide baseline data for other researchers with regards to Self Help Groups. The results would also be useful for capacity building of Self Help Groups' leaderships. Furthermore, leaders in these women groups may use the results to put up strategies on how best to sustain these Self Help Groups. With this important data, stakeholders and government can make informed decisions and strategize on how best shape policy directions to promote microeconomic empowerment of women folks.

\section{LITERATURE REVIEW}

\section{Background and definition of SHGs}

According to Gadanayak (2008), the first Self Help Groups were started and established in 1975 in Bangladesh at Grameen Bank by Mohammed Yunus. But the real effort was taken after 1991-92 from the linkage of Self Help Groups with the banks in India. Because India was raged by high prevalence of poverty, Mohammed Yunus thought of a more attractive scheme with less effort as a tool to remove poverty and improve the women entrepreneurship and financial support in India by Roy (2009).

A Self Help Group is a small economically homogeneous affinity group of the rural poor voluntarily coming together to save a small amount regularly, which is deposited in a common fund to meet members' emergency needs and to provide collateral free loans decided by the group. These Groups are recognized as a useful tool to help the poor rural women and as an alternative mechanism to meet the urgent credit needs of poor group members through saving habit. Gadanayak (2008) state that Self Help Groups enhances the equality of status of women as participants, decision-makers and beneficiaries in the democratic, economic, social and cultural spheres of life.

\section{Principles of SHGs}

The basic principles of the Self Help Groups as emphasised by Harper (2002) are group approach, mutual trust, organization of small and manageable groups, group cohesiveness, spirit of thrift, demand based lending, collateral free, women friendly loan, peer group pressure in repayment, skill training, capacity building and empowerment.

According to Mandal (2005), 'Women need to be viewed not as beneficiaries but as active participants in the progress of development and change empowerment of women could be organized into groups for community participation as well as for assertion of their rights in various, services related to their economic and social well-being". Manimekalai and Rajeswari (2002), conducted a study on "Grass roots entrepreneurship through Self Help Groups (SHGs)", with the objective to find out the factors which have motivated women to become Self Help Group members and eventually entrepreneurs, and analyzed the enterprise performance of Self Help Groups in terms of growth of investment, turnover, capacity utilization, profit etc.

\section{Performance of SHGs}

The analysis showed that the Self Help Group entrepreneurs have improved a lot, with respect to their enterprise performance. The study further observed that the women had been depending only on agriculture and now have become independent. Apart from the improvement on the personal growth, the community as a whole has gained through the organization of the Self Help Groups. Nath (2008), in his discussion paper titled "Self Help Groups in empowering women; case study of selected Self Help Groups and 
Neighbour Hood Groups (NHGs)", gives a review of progress of Self Help Groups. He has attempted to examine the performance of selected Self Help Groups and NHGs and to assess its Effectiveness, especially the Effectiveness of micro credit programme on empowering women. It has been clearly established that delivering credit alone may not produce the desired Effectiveness. The supporting services and structures through which credit is delivered remaining from group formation and training to awareness raising and a wide range of other supporting measures are critical to make the Effectiveness of group activity strong and sustainable. It was this clarity that prompted the researcher to undertake this study to ascertain the Effectiveness of SHGs on women's welfare and explore the challenges faced by women engaged in these SHGs.

Shetty (2001) conducted a study on "Self Help Groups and Social change" with the objective to study the improved status and quality of life of poor women and children in the rural areas and the involvement of community in planning. To achieve the objectives of the study a sample of 1.5 percent, out of 2.19 lakh self-help group in Andra Pradesh, was taken. It is observed that the self-interest and self-motivation would go a long way for the sustenance of the group. The share of women in decision making regarding important domestic matter is varying between districts and cluster groups.

Mahendra Varman P. (2005), in a paper entitled "Effectiveness of Self Help Groups on formal banking Habits", made a model attempt to examine whether there was any association between the growth of Self Help Groups and the increase in female bank deposit accounts and whether Self Help Groups had a tendency to influence account holding in formal banks among individual households. The analysis also revealed that being a member in Self Help Groups and more importantly having leadership experience in Self Help Groups greatly influence the bank account holding. Leadership experience in Self Help Groups would also improve an individual banking habits. However, the assessment of the feasibility of businesses run by SHGs and individuals belonging to these SHGs was not explored thereby creating a knowledge gap for further research to be undertaken.

Dr S. Rajamohan in his study "opinion of the members of self-help groups (2005)" revealed that Self Help Group helps them to increase their status and aids to raise the standard of living. Women are becoming entrepreneurs with the help of Self Help Groups which avoids the exploitation of women and helps empowering them.

Prasad (2006), in his research "SHGs is highly relevant to make the people of below poverty line hopeful" says the very existence of SHGs is highly relevant to make the people of below poverty line hopeful and self-reliant. SHGs enable to increase their income and improve their standard of living and status in society to the main stream ultimately, the nation reaps the advantages of socialism. The economic and social inequalities rooted in traditions and cultural norms need to be changed as political measures alone cannot bring empowerment rural women and youth. While we appreciate the amount of knowledge these scholars have contributed with regard to the performance of SHGs, much still needs to be investigated on the challenges SHGs and their members face in attaining the full benefit of the SHG concept in developing countries such as Zambia.

\section{Challenges women face in SHGs}

According to recent reports coming from India where these women SHGs originated show that, in spite of their remarkable contribution to women empowerment, women SHGs face a number of challenges. (Shetty, 2001) Report indicates sustaining even a small-scale business becomes a big challenge for women SHGs. Broadly, these challenges arise due to lack of knowledge related to technical and management aspects of running a business and certain socio-cultural factors.

\section{Poor Marketing}

It has been vividly noted in India that marketing is the major challenge most SHGs face, When SHG members were asked the following was their response; "Marketing is a hurdle for us. We do not know how to market our products and the different channels used for It." said Surekha, Marketing plays a crucial role to gain visibility for the products. Mtonga (2020) state that lack of effective marketing is a hindrance as this poses a challenge for getting sales orders for the products.

Lack of Product Standardization and Quality Issues.

Most of the products made by SHGs are not uniform in their specifications and look \& feel. This is so because most of the SHG products are hand-made, and hence it becomes difficult to maintain uniformity. Also, to cut costs, (Prasad, 1986) SHGs compromise on quality of raw materials used. This results in products of inferior quality thus affecting customer perception about the SHG

\section{Lack of Vision and Professionalism}

Members of SHGs are mostly semi-literate or illiterate and are ignorant of basic rules pertaining to the formation and conduct of SHGs. This lack of awareness is further compounded by their myopic vision. Beyond immediate financial gains, they are blind towards the vast potential of what they can achieve through a SHG. Usually, running the business is of low priority for many members during festivals and vacation periods in spite of high demand. This lack of professionalism adversely Effectiveness the SHG's business prospects.

\section{METHODOLOGY}

\section{Research Design}

The research design that was adopted in this study was based on quantitative approach due to the nature of the study. The choice of this particular study design was based on grounds that quantitative approach allows respondents to present their views and experiences about the effectiveness of SHGs in poverty alleviation issues among the rural poor communities 
more especially women in the depth of their knowledge. Furthermore, by adopting the qualitative approach, the research attempted to understand the subjective reality from the perspective of an insider as opposed to the outsider's perspective that is predominant in the quantitative approach (Creswell, 2005; De Vos, Strydom, Ouche \& Delport, 2005).

All in all, in the case of this study, the research attempted to understand the subjective views of women involved in SHGs regarding the Effectiveness of SHGs on women's social economic wellbeing for which qualitative approach was most effective.

\section{Target Population}

The study targeted seven (7) clusters of SHGs operating under the umbrella of Katete District women Development Association (KDWDA). Out of the seven clusters, four clusters were randomly selected from which four SHGs were further sampled. Further, from each Self Help group five (5) respondents were selected for the interview. In total four clusters comprising a total of 16 SHGs were used for data collection in this research. The total number of women involved in SHGs in Katete are 1190 coming from 70 different SHGs in all parts of Katete. The clustered sampled were:

$$
\begin{array}{cl}
\text { i. } & \text { Chinkhombe } \\
\text { ii. } & \text { Chiyambi } \\
\text { iii. } & \text { Chiyembekezo, and } \\
\text { iv. } & \text { Talingana }
\end{array}
$$

\section{Study Sample}

The sample size was 80 (eighty) respondents representing $6.7 \%$ of the entire population of women involved in women groups in Katete district. While this sample population was small as compared to the entire population, the percentage of the number of SHGs used was $22.9 \%$ (16/70) within the range of the recommended sample size for research (20-30\%).

\section{Research Instruments}

The researcher used a questionnaire as the main data collection tool which was administered to randomly selected Self Help Group members.

\section{Data Collection}

The study used secondary data from KDWDA to identify clusters and SHGs from which respondents were randomly sampled. Primary data from which conclusions were derived was collected by using structured interview questionnaires. The questionnaire contained close ended questions as well as a few open ended ones designed to answer research objectives. The open-ended questions were used so as to get views and experiences about the Effectiveness of SHGs on social economic wellbeing of women in the depth of the knowledge of respondents.

\section{Data Analysis}

Data analysis involved reading through data collection tools (Questionnaires) which were used in identifying similar responses to give the general overview of the respondents. A questionnaire was divided into close ended questions and open ended questions. All close ended questions in the questionnaire were coded and analyzed while open ended questions were thoroughly analyzed using content and thematic analysis. The analysis was done in form of simple counting and then converting figures to percentages for further interpretation. The analysis was manually done with no computer aid except on drawing graphs and tables. This was because the number of respondents was smaller and the research method used was qualitative which made it difficult to use computer statistical packages like Excel and SPSS. The objectives of the research were diligently compared with the findings and then conclusions and recommendations drawn.

\section{Limitations of the Study}

Limitation of the research must be understood. Even as we recognise some of the constraints associated with research, it is also important to acknowledge the complexity nature of evaluation in a SHGs Cluster context. Some SHGs have been in existence for longer period while others have just been created.

For any research to pass the test as "scientific" sample population must be collected using the random sampling method to reduce biasness. This is not the case in this research due to the fact that randomised studies are not only extremely difficult, expensive, and time-consuming, but also particularly challenging to identify "control groups". Further differences in the periods of existence of these schools as well as accessibility and literacy levels of SHGs to be used as respondents need to be considered as quality of information to be collected is concerned.

In this regard, the research study will be conducted in five (5) SHGs clusters in Katete district. These SHGs are sampled from 230 SHGs in Katete district. These SHGs were also selected based on the year of establishment which are deemed to provide the much needed information for the research. As far as period of existence, these women groups are believed to be a homogenous sample of SHG clusters in Katete District.

\section{DATA PRESENTATION AND ANALYSIS OF FINDINGS}

\section{Introduction}

This chapter presents the analysis and findings of the study. The findings are presented following the research questions. The data obtained from the questionnaires, discussion and observation check list were analysed thematically by identifying information from the data which were important for the study. The data obtained were presented in tabular form, percentages, pie chart and bar graphs. This chapter also presents the demographic information of the respondents. 


\section{Data Presentation}

The presentation has been done in relation to the demographic characteristics and the research question of the study. Data has first being presented and then interpreted.

\section{Demographic Characteristics of Participants}

The demographic information of interest to this study were: gender, age, education level and occupation. The demographic profile has influence on the way different bio data are treated in relation to social economic interventions. Data collected from 80 women sampled from different SHGs were analysed and the results are as summarised below

\section{Marital Status of Respondent}

Marital status of respondents was of interest to the study because it was used to further analyse the support of spouses (husbands) in engaging women in income generating activities. Marital status was also important in order to examine the majority response with regard to the concept of SHGs. The garnered information on marital status of respondents is summarised in the table below.

Table 1: Marital status of Respondents

\begin{tabular}{|c|c|c|}
\hline Category & Frequency & Percentage (\%) \\
\hline Single & 8 & 10 \\
\hline Married & 68 & 85 \\
\hline Divorced & 4 & 5 \\
\hline Widowed & 0 & 0 \\
\hline
\end{tabular}

The information in the table was analysed and interpreted as in the pie chart below

Figure 1

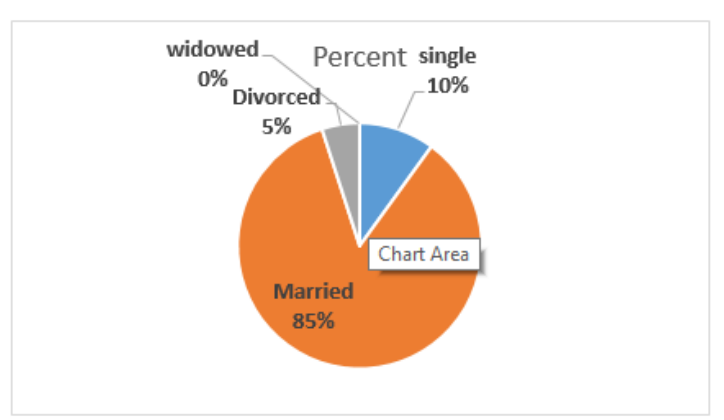

The pie chart above shows that almost 85 of the women involved in SHGs in Katete district are married. This is very good indicator that most men accept, appreciate and support government interventions on gender and women empowerment such as the SHGs concept. On the other hand the findings leaves a question as to why the other categories (singles \& divorced) are very low as they are the ones that needs to be self-reliant.

\section{Age Bracket of Respondents}

The age of respondents (women) was also paramount to this study. Its importance helped in understanding how much knowledge women had with regard to the Effectiveness of SHGs and their sustainability as depicted by the age brackets of respondents. The gathered information on women's age is summarized below.

Figure 2 Age bracket in years

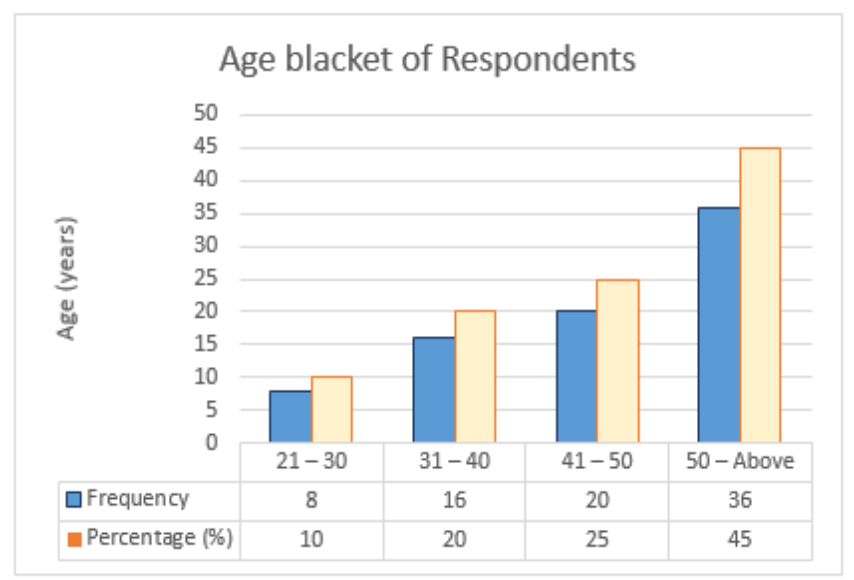

Figure 2 above shows that respondents were unfairly distributed in terms of age. The majority 56(70\%) were aged above 40 years while 24(30\%) were aged below 40 years. Further, only $8(10 \%)$ were aged between $21-30$ years. From these findings it's evident that majority of the women involved in SHGs were aged above 40 years and this could explain why the Effectiveness may not be as much as expected as most of the women engaged are aged with little education. Further, the information corrected makes us question the sustainability of SHG concept as young women with sound education background are not getting involved.

\section{Level of Education of Respondent}

The education level was important to this study because the respondents' level of education influenced the way they implemented the strategies embedded in the SHG concept. The garnered data is shown in the chart below

Figure 3 Frequency Vs Education level

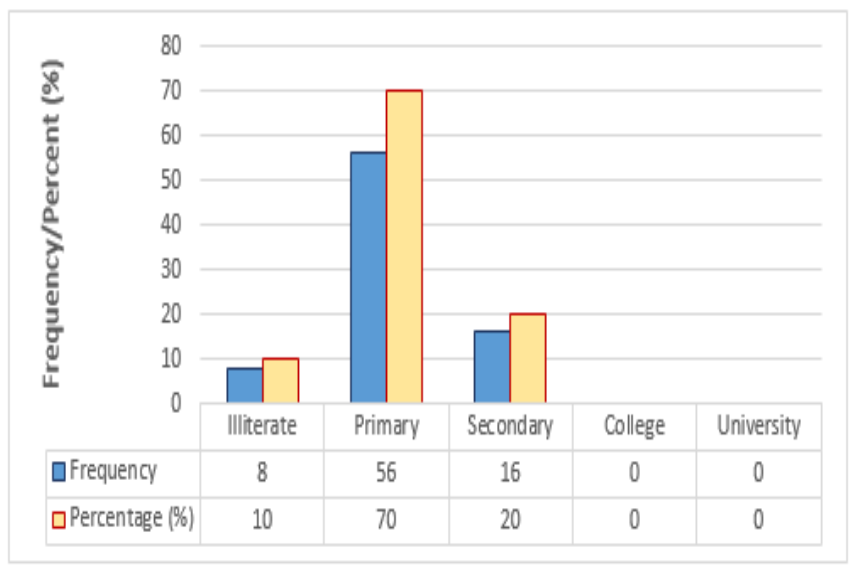

According to the study as shown in figure 3 above, the educational level of respondents was illiterate and primary 
$64(80 \%)$ while $16(20 \%)$ had attained secondary level of education. These findings show that most of women involved in SHGs are illiterate hence business and marketing trainings needs to be undertaken continuously in order to record good results. Further, this information is typical Zambian situation for a rural setup where college and university women are absent. Thus sporadic and occasional trainings are not effective due to lack of information sharing within clusters. Therefore SHGs have remained glued to advocating departments (NGO) longer than two years before being weaned completely.

\section{Occupation of Respondent}

Occupation of respondents was important as it gave an indicator of what proportion of the respondents were actually in business. Further, it gave us indicator of how many employees and business persons had actually adopted the SHG concept. Data collected was as shown in the table below;

Table 2 Occupation of Respondent

\begin{tabular}{|c|c|c|}
\hline Category & Frequency & Percentage (\%) \\
\hline Employed & 0 & 0 \\
\hline Farmer & 12 & 15 \\
\hline Business & 0 & 0 \\
\hline Farmer/Business & 68 & 85 \\
\hline
\end{tabular}

The table above shows that there were no pure employees and business persons who were involved in SHGs. Further, that about $15 \%$ of the respondents were not doing any business meaning that the loans they were getting from SHG were purely used on consumption rather than business. This shows that there was still need to create general awareness on the importance of Income generating activities in SHG if the full benefit was to be realised. On the other hand the results showed that $85 \%$ of the women were not only farming but also doing businesses. This partly indicate a positive Effectiveness of SHG as most of the women in rural areas are now engaged in businesses or income generating activities.

\section{Feasibility of Group Business}

This objective was not analysed completely as most of the respondents $67(83.7 \%$ ) did not consider SHG as village banks which were doing business, neither did they consider it important to do group business with extra servings. Further, even those that answered yes indicated that their group businesses were not registered and could not precisely indicate the costs incurred and profits generated by the group businesses in the last six months. The responses were as shown in the table below:

Table 3 Number of Respondents registered Group Business

\begin{tabular}{|c|c|c|}
\hline \multirow{2}{*}{$\begin{array}{c}\text { Are you part of a SHG } \\
\text { Business? }\end{array}$} & Yes & No \\
\cline { 2 - 3 } & 13 & 67 \\
\cline { 2 - 3 } & 1 & 79 \\
\hline Is the SHG business registered? & &
\end{tabular}

This poses a challenge in terms of auditing and existence of these SHGs once weaned from the advocating NGOs. It goes without saying that for as much as these SHGs start as unregistered entities, it is important to be registered as they grow in order to attain legality and recognition. Once savings grow above the borrowing power of individual group members, the group may initiate soft loans for people with collateral innovatively as a way of group business expansion for example.

This situation of groups staying for years without being registered therefore, is a worrying issue in as far as the development and sustainability of SHGs is concerned.

Feasibility of individual businesses

\section{Business Details}

The information collected showed that all the respondents owned individual businesses, however, only 16 representing $20 \%$ had their businesses registered. The $100 \%$ business ownership scenario contradict the results of occupation above which indicated that $15 \%$ of women were purely farmers as established in section 4.4 .4 above.

Figure 4 Proportion of Individual businesses Registered

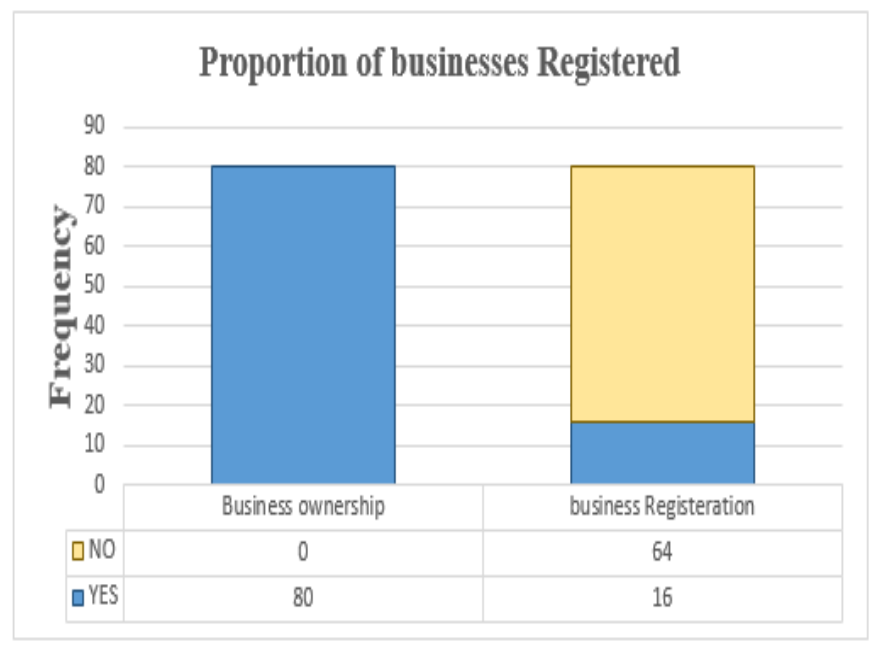

Thus while it could be true that almost all women involved in SHG had income generating activities, the feasibility standing of these IGAs is further questioned by the fact that only $20 \%$ had actually registered businesses as indicated above.

\section{Type of Business}

The results showed that men businesses done by women in SHGs were Grocery and broiler poultry production which stood at $40 \%$ of total interviewed. These were followed by gardening and other businesses such milling and oil expellers which was done by almost $35 \%$ of the women. Community Agro dealers were 12 representing $15 \%$ of the population 
Table 4 Type of Business undertaken women involved in SHG

\begin{tabular}{|c|c|c|}
\hline Type of Business & Frequency & Percentage (\%) \\
\hline Grocery & 32 & 40 \\
\hline Poultry & 32 & 40 \\
\hline Agro-Shop & 12 & 15 \\
\hline Piggery & 4 & 5 \\
\hline Gardening & 28 & 35 \\
\hline Others & 28 & 35 \\
\hline
\end{tabular}

All in all, most women were engaged in agricultural related business except just a few who were also doing grocery.

Capital investment of individual Business in the past six months

Data collected showed that average costs/capital of businesses owned by women in the last six months was ranging from K398.00 to 462.75 per month. These averages however of less significance as was shown by large standard deviation calculated indicating a wider variation in the business capital requirement done by the women.

Table 5 Capital investment of individual Business in the past six months

\begin{tabular}{|c|c|c|c|}
\hline Month & Profit & Costs & $\begin{array}{c}\text { Returns to } \\
\text { Investment }\end{array}$ \\
\hline March 2017 & $462.75 \pm 394.2$ & $863.5 \pm 858.3$ & 53.6 \\
\hline February 2017 & $\begin{array}{c}380.10 \pm \\
278.70\end{array}$ & $720.75 \pm 700.5$ & 52.7 \\
\hline January 2017 & $250.00 \pm 56.40$ & $\begin{array}{c}580.50 \pm \\
564.75\end{array}$ & 43.06 \\
\hline Dec 2016 & $263.50 \pm 240$ & $\begin{array}{c}591.25 \pm \\
511.20\end{array}$ & 44.5 \\
\hline $\begin{array}{c}\text { November } \\
2016\end{array}$ & $120.40 \pm 78.6$ & $\begin{array}{c}400.00 \pm \\
375.00\end{array}$ & 30.1 \\
\hline
\end{tabular}

On the other hand the sample means were paramount in determining the trends in the growth rates of capital/cost, profits and returns to investments as shown in the figure below. The figure shows that on average, businesses as well as the returns to investment have been growing steadily from October, 2016 to March 2017. This does not only indicate an improvement in business experience but also financial discipline of SHG members as the figure increased from left to right as shown by the allow.

Figure 5 performance of individual businesses in the last 6 months

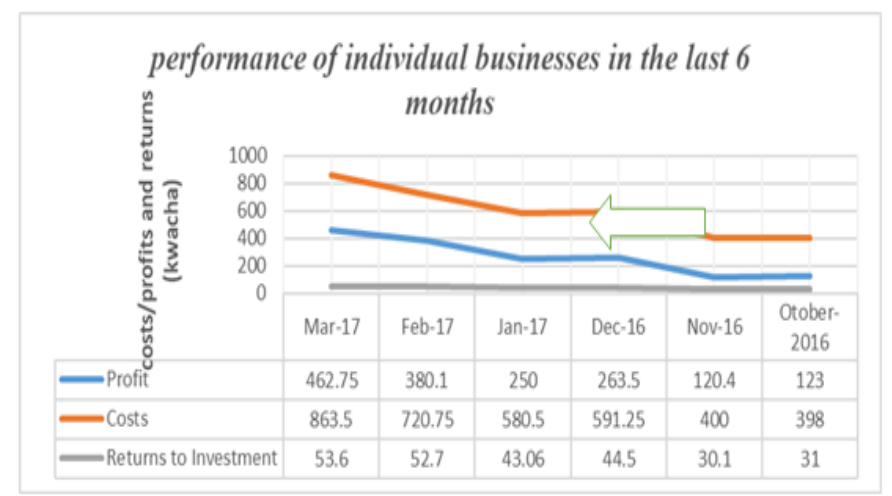

\section{CHALLENGES}

\section{General Challenges}

Generally the research identified five major challenges faced by women in doing business in rural areas. The challenges were; Financial, Marketing, Low/lack of inputs, domestic, and inadequate loans. When respondents were asked to tick the main challenge affecting their individual businesses, the results were as shown in the pie chart below.

Figure 6 General Challenges

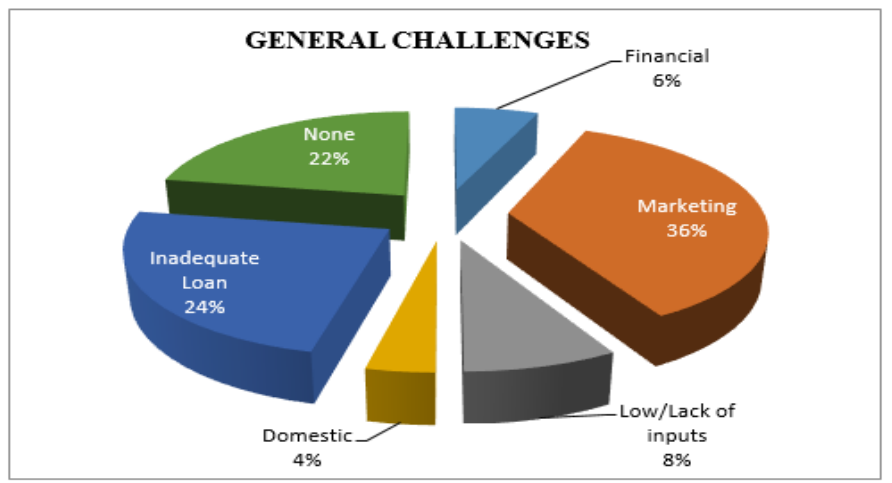

Results obtained showed that Marketing (36\%) was the major challenge, followed by inadequate loan

\section{Training Challenges}

The section was examined the exposure of respondents to business oriented trainings to establish traces of knowledge in business management. Results showed that all respondents were at least attended a business training. As most of respondents $(80 \%)$ had only gone up to primary level, the importance of training therefore, cannot be over emphasized.

While we appreciate the fact the KDWDA had subjected the women to training, it is also important to note the effectiveness of trainings is dependent on the frequency at which they are undertaken. The more often they are administered, the more effective they become especially that the age group involved was aged women. Considering the results shown in the figure below, it was evident that lack of training was not a challenge to women groups in Katete district.

Figure 7: Types of Trainings undertaken by SHG members

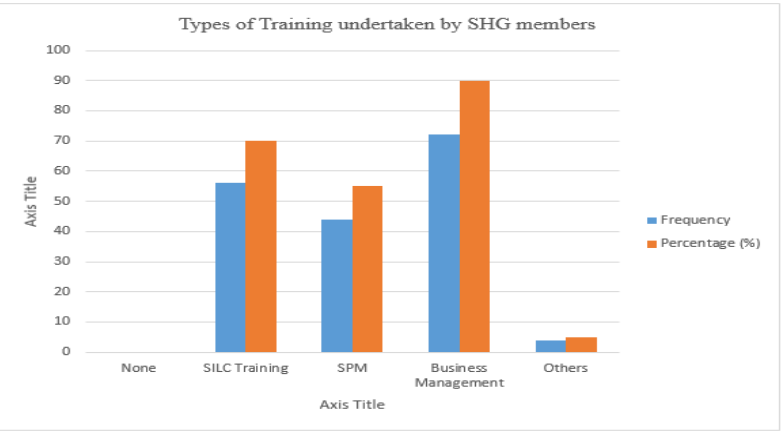




\section{DOMESTIC INTERFERENCES / DECISIONS}

The section was meant to establish traces of spouse interference in critical decision making stages of the day to day running of individual business. The results obtained showed that women were able to make decisions on their own. Further, that for the married women not at any time was the decision left to their husbands to make independent decisions.

This was evident when no respondent that spouses alone where responsible to decide how the loan was to be utilized, in making final decisions, and business management. This meant that even though women appreciated the presence of man in their lives, they were courageous enough to make independent decisions as shown on the figure belo

Figure 9 Domestic interference and decision making

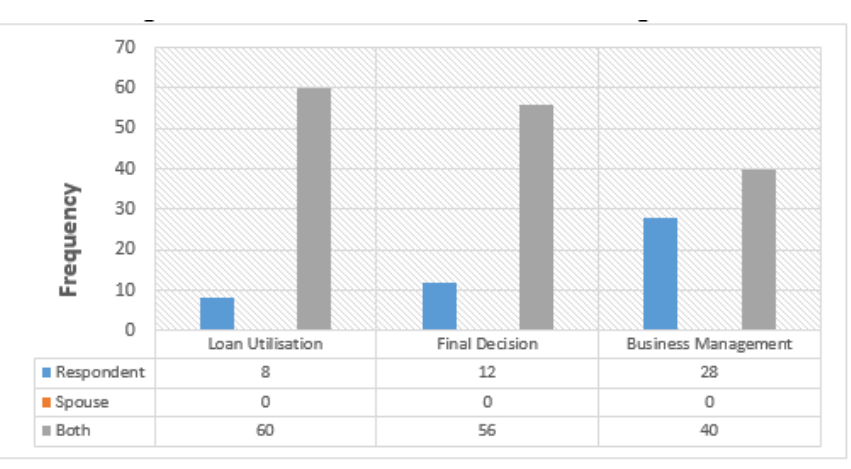

Economic Status of SHG Members

On economic status of SHG members, it was established that all the women acknowledged that their involvement in SHGs had improved their social economic status. The respondents were further asked to state their financial status then, how they utilized the loans obtained from SHG, and also state the areas which had greatly improved due to their involvement in SHGs. These were meant to further establish the social economic areas which had been positively Effectiveness by the SHG concept.

\section{FINANCIAL STATUS}

When respondents were asked to state the current financial using structured responses as shown in the table below, it was established that most of the rural women had enough money for food and clothes but short of many other things (70). Further, 25\% of the respondents indicated that had most important things but few luxury things. These results therefore clearly indicate that the SHG concept has greatly contributed to women empowerment in the sense that they able to meet their basic needs; shelter, food and clothes.

Table: Current Financial Status

\begin{tabular}{|c|c|c|}
\hline Current Financial Status & Frequency & $\begin{array}{c}\text { Percentage } \\
(\%)\end{array}$ \\
\hline Not enough money for food & 0 & 0 \\
\hline $\begin{array}{c}\text { Enough money for food but no other basic } \\
\text { needs }\end{array}$ & 4 & 5 \\
\hline $\begin{array}{c}\text { Enough money for food and clothes but short } \\
\text { of many other things }\end{array}$ & 56 & 70 \\
\hline
\end{tabular}

\begin{tabular}{|c|c|c|}
\hline $\begin{array}{c}\text { Have most important things but few luxury } \\
\text { things }\end{array}$ & 20 & 25 \\
\hline $\begin{array}{c}\text { Have money for luxury goods and extra } \\
\text { things }\end{array}$ & 0 & 0 \\
\hline
\end{tabular}

\section{Loan utilisation}

This section was meant to examine the main use of soft loans obtained from the SHG. The use of income determines the ultimate Effectiveness of the person of the very income. There are generally two main uses of income namely; consumption and investment where savings is not an option. Whereas consumption meets immediate needs, investment is more sustainable and recommended for the loans obtained from SHGs.

Figure 10: General Challenge

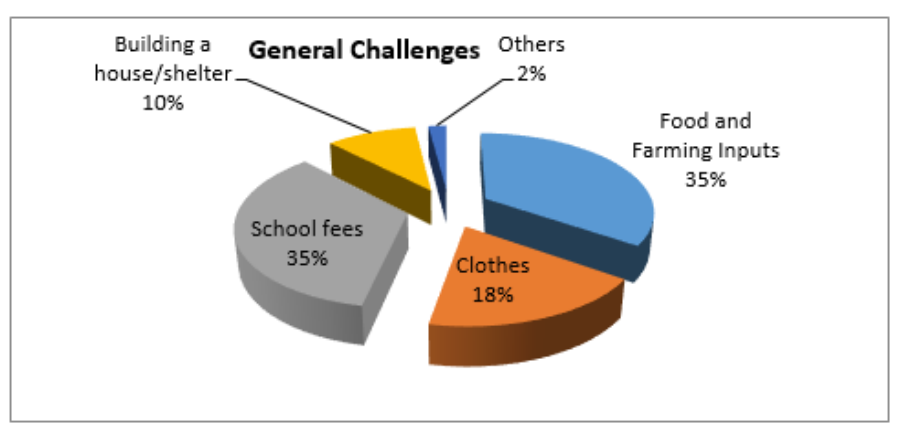

\section{Area improved due to SHG involvement}

This part of the research was meant to compare the socioeconomic status of the respondents before they joined these women groups and to determine which areas of their livelihood had improved after they joined Self Help Groupings. From the sampled population, it was observed that social fund, household savings and paying of school fees greatly improved as evidenced by the table presented below.

The concept of SHG is to enhance the quality of life of rural women as participants, enhance their decision-making in the democratic, economic, social and cultural spheres of life. It was further observed that health care and household expenditure and welfare did not receive adequate attention.

Table: Area improved due to SHG involvement

\begin{tabular}{|c|c|c|}
\hline $\begin{array}{c}\text { Area that has improved greatly due to } \\
\text { involvement in SHG }\end{array}$ & Frequency & $\begin{array}{c}\text { Percentage } \\
(\%)\end{array}$ \\
\hline Social Fund & 48 & 60 \\
\hline Household savings & 52 & 65 \\
\hline Household expenditure and welfare & 16 & 20 \\
\hline Health Care & 20 & 25 \\
\hline Food security and nutrition & 32 & 40 \\
\hline Availability of Farming inputs & 36 & 45 \\
\hline Paying of School Fees & 60 & 75 \\
\hline
\end{tabular}

Summary of Research Findings

In summary the results obtained from this research showed the following Effectiveness on the socio-economic wellbeing of women in Katete District. 
i. The SHG had an Effectiveness on the aged (70\%), illiterate $(80 \%)$ and married respondents $(85 \%)$ who are actively involved in SHGs.

ii. However, $15 \%$ of women involved in SHGs were purely involved in farming with no business activities

iii. No SHG was conducting business as a group apart from one respondent who indicated was doing poultry business.

iv. Almost all women involved in SHGs own businesses. However, only $20 \%$ of these businesses were registered.

v. Capital investment ranged from K398.00 - K462.75 with returns to investment ranging from 0.3 to 0.5 per every kwacha involved. Therefore, individual businesses were feasible.

vi. However lack of market (36\%) and inadequate loan facilities $(24 \%)$ were considered the major challenges affecting businesses owned by women belonging to SHGs

vii. Lack of training and domestic interference were not part of challenges affecting business ran by these women.

viii. Respondents acknowledged/ indicated that their involvement in SHG had positively improved their socio-economic status

ix. Financially, women in these villages indicated having enough money for basic needs such as clothes, shelter and food. Further, the loans obtained from these SHGs were mainly used for school fees (35\%), food and farming inputs $(35 \%)$ and clothes (18\%) representing a total of $98 \%$ in basic needs including shelter $(10 \%)$

x. The respondents further acknowledged that three areas had greatly improved due to the involvement in Self Help Groups namely payments of school fees (75\%), Household savings (65\%) and social funds $(60 \%)$

\section{CONCLUSIONS AND RECOMMENDATIONS}

\section{Conclusion}

Following results of this research, it was concluded that SHGs had a positive Effectiveness on the social economic wellbeing of women in Katete district especially the aged $(70 \%)$, the illiterate $(80 \%)$, and married women representing $85 \%$ of the entire population. hence, can become a major catalyst in turning around the rural economy along with achieving the goal of women empowerment. However their success will depend on adequate support from passionately engaged stakeholders such as NGOs which should be aimed at addressing marketing challenges.

\section{Recommendations}

For the SHG movement to be successful, other players and stakeholders need to step in to support and promote it. Government, Micro-finance institutions, Non-Governmental
Organizations, NGOs and other intermediaries can play a key role in motivating, training and guiding the SHGs. They can organise campaigns to spread awareness related to government schemes, and knowledge related to marketing and finance.

Passionately engaged stakeholders such as NGOs and CBOs like KDWDA should immediately address issues of lack of business registration and lack of group businesses which questions the legality of these businesses. Further, the concept of SHGs is inclined on the engagement of rural women in income generating activities, hence, the $15 \%$ of women who were established to be purely farmers needs to be sensitized on the importance of engaging in IGAs.

While this research examined the feasibility of individual businesses, economic Effectiveness of SHGs and challenges affecting the success of SHGs, further research needs to be undertaken to investigate causes of low participation of women of other social groupings such as; the learned, singles, widows and young women.

Effective engagement periods for pro-SHGs organization with the respective SHGs in extremely illiterate rural communities should further be explored. This due to the fact that the recommended two years engagement periods may not be convenient for developing countries like Zambia were most of the women only managed to reach primary level of education.

\section{ACKNOWLEDGEMENTS}

There were days once I was sad, thinking whether I might be ready to complete the Thesis. Then, my supervisors, friends, family members, faculty at the Texila American University, and colleagues encouraged me to tread on the path. I am sure; I even have forgotten many of us who would have helped me. Exceedingly, I express my appreciation to all those who stimulated and helped me directly or indirectly in this journey.

Most sincerely, I wish to thank my Supervisors, Professor Aruwa, Suleiman Akwuodo Salihu, and Dr Rheeta Marjery for guiding me conscientiously in writing the Thesis. I will remain greatly indebted to them for their commitment and dedication to academic work.

My sincere gratitude goes to the Texila American University management team and support staff for their tireless support. I also thank my employer Ministry of Agricultural, Katete College of Agricultural Management, to take leave to attend online classes and examinations particularly the Principal $\mathrm{Mr}$ John K Nkole.

\section{CONFLICT OF INTEREST}

In this research there was a balance between protecting sources of knowledge and a search for knowledge. The subsequent ethical rules of research were strictly adhered to. Hence no conflict of interest. 


\section{REFERENCES}

[1] Bhagyalakshmi, J. (2004). "Empowerment of Women and Marginalised Groups in Panchayats","Rural Development through Women's Participation and Electronic Media. Jaipur: Pointer Publication.

[2] Gadanayak, B. B. (2008). "Poverty alleviation at the grass root level, self-help groups as an instrument" Dev4India.org.

[3] Harper, M. (2002). "Practical Micro finance: A Training guide for South Asia". New Delhi: Vistaar Publication.

[4] Karmakar, K. G. (1999). "Rural Credit and Self-help Group, Micro finannce Needs and Concept in India". New Delhi: Sage Publication.

[5] Mandal, A. (2005). "Swarnajayanti Gram Swarozgar Yjana and Self-help group: An Assessment" Kurukshetra. A Journal of Ministry of Rural Development.

[6] Mtonga, E. (2020) 'The Prevalence of Locally Owned Enterprises and Their Role in Economic Growth and Development in Chipata
District of Zambia', Texila International Journal of Management, 6(1), pp. 24-31. doi: 10.21522/tijmg.2015.06.01.art003

[7] Nath, D. (2008). "Selp-help Group and Women Empowerment, Assam Tribune Online.

[8] Prasad, K. (1986). "Poverty in Rural India", "Studies in India Agriculture and Rural Development". New Delhi: Deep and Deep Publication.

[9] Roy, P. (2009). Creating a World Without Poverty: Social Business and the Future of Capitalism. Social Change, 39(2), 299302. https://doi.org/10.1177/004908570903900209

[10] Shetty, S. L. (2001). "Rapporteur's Report on Working and Effectiveness of Self-help Groups and other Forms of Micro financing". Indian Journal of Agricultural Economics, 580-604.

[11] Shylendra, H. S. (2004). "The SHG_Bank Linkage Programme, An Assessment and Future strategies". Journal of Rural Development, a quartery of NIRD.

[12] http://www.nabard.org.in

[13] http://www.rural.nic.in

[14] http://www.pbplanning.gov.in 